\title{
Numerical study of the inner canalization geometry optimization in a milling tool used in micro quantity lubrication
}

\author{
A. Duchosal ${ }^{1, a}$, R. Serra ${ }^{2}$ And R. Leroy ${ }^{3}$ \\ 1 Laboratoire de Tribologie et Dynamique des Systèmes, 58 rue Jean Parot, 42023 Saint-Étienne, France \\ 2 INSA Centre Val de Loire, Laboratoire de Mécanique et Rhéologie, 3 rue de la Chocolaterie, 41000 Blois, France \\ 3 Polytech' Tours, Laboratoire de Mécanique et Rhéologie, 7 avenue Marcel Dassault, 37200 Tours, France
}

Received 14 December 2013, Accepted 31 May 2014

\begin{abstract}
This study focused on numerical analysis of the parameters influencing the oil mist flow (MQL) outside a rotating tool, in non-contact configuration. This approach was a mandatory step for the parameter optimizations before taking into account the material removing. The optimization of inner canalization geometries to a milling tool was performed to transfer the oil mist. The Reynolds Average Navier Stokes (RANS) and Lagrangian equations were used to simulate the oil mist flow inside the canalizations by integrating the standard $k-\varepsilon$ turbulence model with the STAR CCM+ commercial software. The dynamic numerical calculation was used to optimize the inner canalizations of a milling tool. Because of the particular external tool shape, the micro spray cooling is not guaranteed to reach the cutting edge. The external tool geometry, the inlet pressure, the shape and the orientation of the inner canalization geometries in the tool body and the rotation speed have significant influence on the lubrication efficiency. The main goal of this study was to improve this efficiency as function of these parameters. Thus, parameter sets giving good lubrication were determinate for a type of tool.
\end{abstract}

Key words: Minimum quantity lubricant / CFD / multiphase flow / milling tools / inner canalization geometries

\section{Introduction}

MQL (Minimum Quantity Lubrication) has been used extensively in various mechanical industries (automotive, aeronautic, etc.). The MQL process offered very small oil consumption and benefic effects on machining (surface state, increased tool life time...) [1-3]. Moreover the MQL coolant technique is used to machine hardened steel and offered very good cutting performances (cutting temperature and surface roughness), regardless wet and dry lubrication techniques. MQL parameters were then optimized as function of the cutting parameters: i.e. higher the pressure at the exit of nozzle, better the flank wears [4].

The two-phase air + oil mixture which made up MQL was created either outside or inside the spindle [5]. In the first case, the two-phase fluid may be ejected by external nozzles directly and wisely oriented on the cutting edge. However, the position of the outside nozzles and their orientation require careful attention, as shown by Lopez de Lacalle [3]. On the other hand, the two-phase mixture

\footnotetext{
${ }^{a}$ Corresponding author: arnaud.duchosal@enise.fr
}

may go through the inside of the spindle and the tool body by an inner channel. The inner canalizations network has to be study to ensure the lubricant efficiency. Turning tools did not require particular study. The oil mist was easily sprayed on the cutting edge. Eventual aerodynamic effects did not have to be considered [6,7]. In grooving machining, the position of the external nozzle has been also studied. The grooving tool produces air layer around the wheel periphery, which affects grinding lubrication efficiency. Thus, nozzle position and distance and the lubricant and gas flow rate have significant effects on lubrication efficiency and also on cutting forces and surface roughness. In this study the author highlighted the influence of the gas flow with high speed camera. By increasing the gas flow rate, the particle sizes were reduced and increased the misting efficiency. High gas flow rate made easier the oil mist spray into the chip-workpiece contact area $[8,9]$.

Rotating tools, as used for drilling [1,11], can be even more susceptible to the aerodynamic phenomenon, since the distance between the outlet of the pipe and the cutting 
edge was very small. Material removal took place in a confined space (drill hole), facilitating optimal lubrication. But in certain cases, machining ductile material as 303, 304 or 316 L stainless steels with MQL coolant technique is poor. The pressurized air of the micro pulverization does not reach the air flow rate to blow out chips from holes. The studies of Lopez de Lacalle et al. show the significant effect to have high pressure outside of the internal canalizations, regardless the roughness and the number of holes produced [10]. There were few studies on milling machining with minimal fluid coolant by internal channels. All studies to date have focused on external MQL $[3,12]$. Aoyama's study dealt with the influence of spindle rotation and inlet pressure on particle sizes in numerical simulation [1]. His results showed the influence of pressure and the effect of rotation of the channel on particle size with STAR CD numerical simulation software. It was clear that small particle sizes $(\varnothing<1 \mu \mathrm{m})$ were much less subject to the effects of rotation, and there were more small particles than particles in the range of $\varnothing 10 \mu \mathrm{m}$ (Ratio of 1:5).

Numerical simulation was required to observe and explore the oil mist behavior with canalization geometries and different inlet (Inlet pressure) and outlet (Machining configurations) conditions.

Li et al. gave an overview of the RANS flow patterns (Reynolds-Average Navier-Stokes) which was largely used for simulating the continuous flow [13]. The developed multiphase models have given very good results regarding particle behaviors. The Euler-Lagrange model was largely used for the diphasic flow study [14-16]. Moreover, the standard $\mathrm{k}-\varepsilon$ turbulence model was easily integrated to E-L model. The oil mist was constituted of very small particles of about $0.1 \mu \mathrm{m}<\varnothing<100 \mu \mathrm{m}$. The inertia was thus neglected in the continuous phase flow, as the particle interactions. Therefore, the dispersed phase has no influence on the continuous phase behavior [17]. The particle tracks were studied with the Lagrangian model by analyzing their velocities [18].

The study consisted in optimizing the inner canalization geometries of a rotating tool used in a surfacing process, with a no removal material approach.

Several inlet (three inlet pressures) and outlet (three rotation speeds) conditions were considered scanning a large range of machining conditions. These conditions created aerodynamic effects due to the particular geometry of the rotating tool.

The first part was devoted to the motion equations used in the commercial STAR CCM+ software. The very good experiment versus numerical outlet velocities enabled to consider in the second part, the rotation of the milling tool. The oil mist sprayed on the cutting edge was thus analyzed to find the optimal canalization geometries.

\section{Governing equations}

The simulations treated in this paper were a threedimensional steady flow which involved particles in an
Table 1. Constants for the $k-\varepsilon$ turbulence model.

\begin{tabular}{ccccc}
\hline$C_{\mu}$ & $C_{\varepsilon 1}$ & $C_{\varepsilon 2}$ & $\sigma_{k}$ & $\sigma_{\varepsilon}$ \\
\hline 0.09 & 1.44 & 1.92 & 1.0 & 1.3 \\
\hline
\end{tabular}

incompressible gaz. The flow field was isothermal. Fluid motion was described by the continuity equation (Eq. (1)) given by [19]:

$$
\frac{\partial}{\partial t}\left(\rho_{f} \alpha_{f}\right)+\frac{\partial}{\partial x_{j}}\left(\rho_{f} \alpha_{f} u_{f i}\right)=0
$$

where $\rho_{f}$ is the constant density of the gas, $\alpha_{f}$ is the gas volume fraction and $\mathrm{u}_{f}$ is the average velocity of the gas. The momentum equation (Eq. (2)) for the fluid phase was given by:

$$
\begin{array}{r}
\frac{\partial}{\partial t}\left(\rho_{f} \alpha_{f}\right)+\frac{\partial}{\partial x_{j}}\left(\rho_{f} \alpha_{f} u_{f i}\right)=-\frac{\partial P}{\partial x_{j}}+\frac{\partial}{\partial x_{j}}\left[\alpha _ { f } \mu _ { f } \left(\frac{\partial u_{f i}}{\partial x_{j}}\right.\right. \\
\left.\left.+\frac{\partial u_{f j}}{\partial x_{i}}\right)\right]-\frac{2}{3}\left[\alpha_{f} \mu_{f} \frac{\partial u_{f m}}{\partial x_{m}}\right]-F+\rho_{f} \alpha_{f} g_{i}
\end{array}
$$

where $P$ is the pressure in the fluid, $\mu_{f}$ is the viscosity of the fluid phase and $F$ is the rate of momentum exchange per unit volume between the fluid and particle phases.

The standard $k-\varepsilon$ model was one of the most popular turbulence models used in computational fluid dynamics (CFD). This model of turbulence appears to perform satisfactorily [16] and was composed of two transport equations for the turbulent kinetics $k$ (Eq. (3)) and its dissipation rate $\varepsilon$ (Eq. (4)) defined as follows:

$$
\begin{aligned}
\frac{\partial}{\partial t}(\rho k)+\frac{\partial}{\partial x_{j}}\left(\rho u_{j} k\right)= & \frac{\partial}{\partial x_{j}}\left[\left(\mu+\frac{\mu_{t}}{\sigma_{k}}\right) \frac{\partial k}{\partial x_{j}}\right] \\
& -\rho \varepsilon+\tau_{i j} \frac{\partial u_{i j}}{\partial x_{j}} \\
\frac{\partial}{\partial t}(\rho \varepsilon)+\frac{\partial}{\partial x_{j}}\left(\rho u_{j} \varepsilon\right)= & \frac{\partial}{\partial x_{j}}\left[\left(\mu+\frac{\mu_{t}}{\sigma_{\varepsilon}}\right) \frac{\partial \varepsilon}{\partial x_{j}}\right] \\
& +\frac{\varepsilon}{k}\left(C_{\varepsilon 1} \tau_{i j} \frac{\partial u_{i j}}{\partial x_{j}}-\rho C_{\varepsilon 2} \varepsilon\right)
\end{aligned}
$$

with

$$
k=\frac{3}{2}\left(I u_{j}\right)^{2} \quad \text { and } \quad \varepsilon=\frac{C_{\mu}^{3 / 4}}{L} k^{3 / 2},
$$

where $I$ is the turbulence intensity set to 0.1 and $L$ is the length scale set to $0.001 \mathrm{~m}$ in (Eq. (5))

The standard coefficients are given in Table 1 , for the $k-\varepsilon$ model.

Particle phase equations were given by Andrew and O'Rourke [20]. The evolution of the particle phase was governed by a Liouville equation (Eq. (6)) for the particle distribution function $f\left(x_{p}, u_{p}, \rho_{p}, V_{p}, t\right)$, where $x_{p}$ is the particle position, $u_{p}$ is the particle velocity, $\rho_{p}$ is the particle mass and $V_{p}$ is the particle volume:

$$
\frac{\partial f}{\partial t}+\frac{\partial}{\partial x_{p}}\left(f u_{p}\right)+\frac{\partial}{\partial u_{p}}(f A)=0
$$




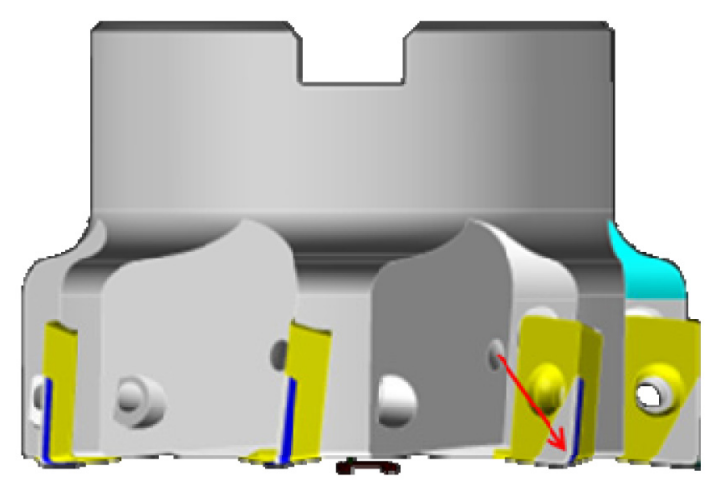

Fig. 1. Illustration of the prototype equipped with its carbide inserts and its spray holes oriented at $45^{\circ}$. The red arrow gives the output direction of the oil mist (air + oil).

In this equation $A=d u_{p} / d t$ is the particle acceleration (Eq. (7)) and was given by:

$$
\begin{aligned}
A= & D_{p}\left(u_{f}-u_{p}\right)-\frac{1}{\rho_{p}} \frac{\partial P}{\partial x_{j}} \\
& +\left(1-\frac{\rho_{f}}{\rho_{p}}\right) g-\frac{1}{\alpha_{p} \rho_{p}} \frac{\partial \tau}{\partial x_{j}}
\end{aligned}
$$

where $\alpha_{p}$ is the particle volume fraction. Equation (7) models acceleration due to hydrodynamic drag, dynamic pressure gradient, net buoyant force and gradients in the interparticles stress $\tau$. $D_{p}$ is the drag function.

The previous Eulerian/Lagrangian formulations ignored the interparticle stress term which was model approach. It can be shown by deriving the average momentum equation (2) that this formulation accounted for the kinetic stress that arise from local particle velocity fluctuations about the mean velocity. Moreover, particleparticle interactions were neglected, so the interparticle stress was set to zero.

\section{Tool rotation simulation}

A previous study highlighted the oil rate parameter setting as functions of input sets [21]. This step considered the simulation of a tool rotation used for the surfacing process, with these parameters. Figure 1 showed the study tool. It was consisted of seven carbide inserts with a diameter of $\varnothing 80 \mathrm{~mm}$ with HSK attachment type.

The main goal of this prototype was to be used in a MQL production line. A main canalization was drilled in the centre of the tool as well as small canalizations (ramifications) in the sides to ensure the oil mist spray on the cutting edge on each insert (red arrow in Fig. 1). The ramifications were oriented at $45^{\circ}$ relative to the vertical axis. For further calculations in simulation, different orientations were considered in this study.

\subsection{Initial conditions - Boundary conditions}

Due to their large range of use, three rotation speeds were considered: 5000, 10000 and $20000 \mathrm{rpm}$. Three
Table 2. Air and oil flow rates as function of inlet pressure.

\begin{tabular}{cccc}
\hline$P_{\text {Inlet }}($ bar $)$ & 0.3 & 0.77 & 1 \\
\hline Air flow rate $\left(1 . \mathrm{min}^{-1}\right)$ & 512 & 784 & 904 \\
Oil flow rate $\left(\mathrm{ml}^{-1} \mathrm{~h}^{-1}\right)$ & & 10 & \\
\hline
\end{tabular}

inlet pressures from experiments were considered: 0.3 bar, 0.77 bar and 1 bar. In previous studies, it has been shown that the most viscous oil retains small particles. The PX 5130 oil is considered here with 0.074 Pa.s dynamic viscosity. Thus, a $10 \mathrm{ml} \cdot \mathrm{h}^{-1}$ oil mist rate with $\varnothing 1 \mu \mathrm{m}$ particle size was used for all the simulations [22]. Outlet conditions were taken as ambient air (1bar absolute pressure) in milling conditions (with workpiece nearby). The following Table 2 summarizes the air flow rate with the constant oil flow rate regardless to the different inlet pressures.

The commercial STAR CCM+ software cannot simulate rotation with deforming mesh. The solution was to consider the rotation with a MRF model (Moving Reference Frame). A constant angular velocity " $\omega_{p}$ " is considered with a position vector from the origin " $r$ " of the moving reference frame to the center of a control volume (parcels of particles). This relative velocity formula is integrated in the momentum equation (Eq. (2)) in terms of velocity and inertial fluid forces. The rotation of the tool thus considered a moving reference frame model in an ambient air (outlet condition). Different rotation speeds were then attributed to the geometric model by changing the value of the angular velocity.

Figure 2 showed the geometric model to simulate the tool rotation. The moving frame was composed of the tool canalizations and the tool (blue contours in Fig. 2). The ambient air modeled by the OUTLET (black contours) included the MRF. The static part simulated also the workpiece nearby with the wall condition above the meshing model. The MRF modeled the oil mist spray in a steady state condition. The oil mist rate and the rotation speeds were then in a steady state condition. The particle tracks obtained with the Lagrangian model outside the canalization defined what happened onto the reality.

The rotation speed and the particular shape of the tool created aerodynamic phenomena. These effects have a significant influence on the behavior of the sprayed oil particles (particle tracks). The spray optimization consisted in the capability of the dispersed phase to reach the cutting edge (zero-based on Fig. 3). Thus, the optimal spray consisted in the capability of the spray projection center on the carbide inserts should be closest to the zero-based.

Figures $3 \mathrm{a}$ and $3 \mathrm{~b}$ showed the two extreme cases of the distance from the spread center in the plan section of the insert relative to the cutting edge. The horizontal axis was indicated by " $-x$ " and the vertical axis was indicated by " $x$ " from the zero-based.

This optimization developed here depended on different parameters:

- canalization diameters to avoid pressure lost;

- inlet conditions $\left(P_{\text {inlet }}\right)$; 


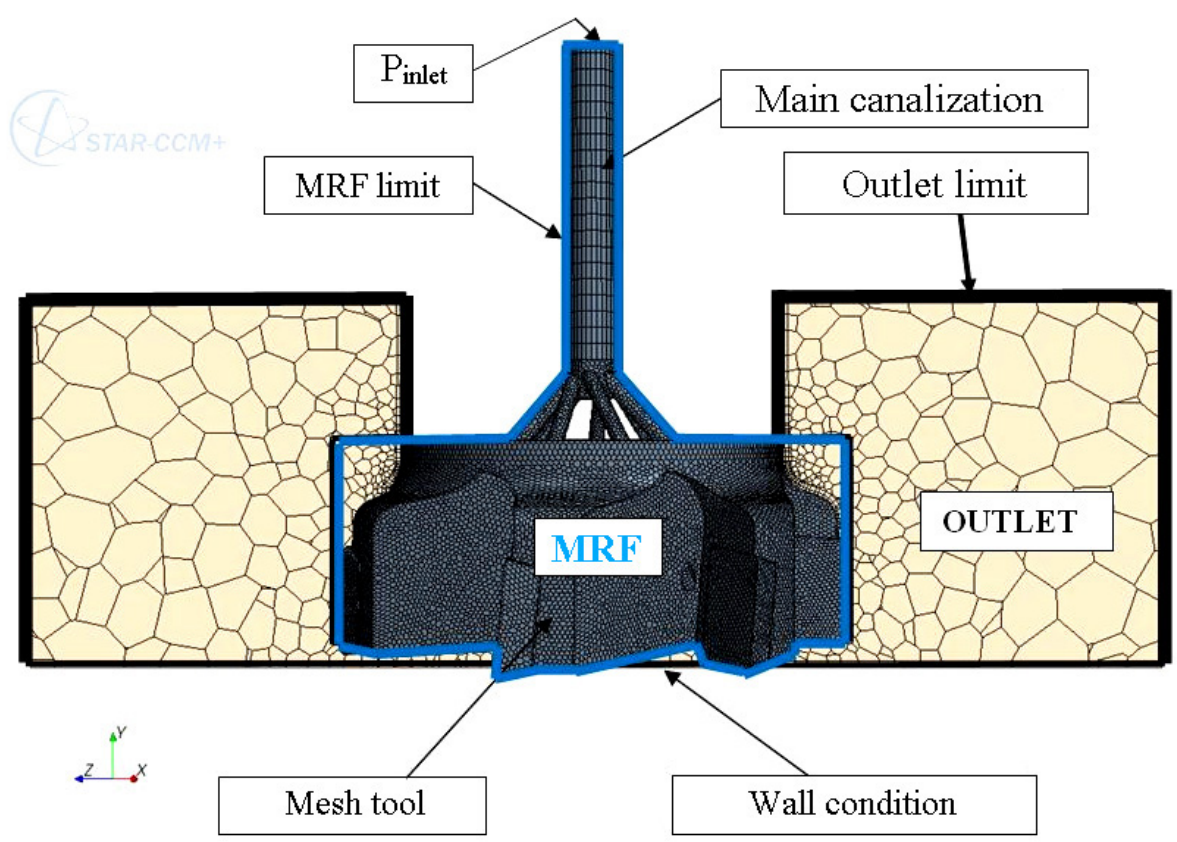

Fig. 2. Illustration of the meshing model. The MRF was consisted of the main and the small $45^{\circ}$ canalizations in the ambient air (OUTLET).

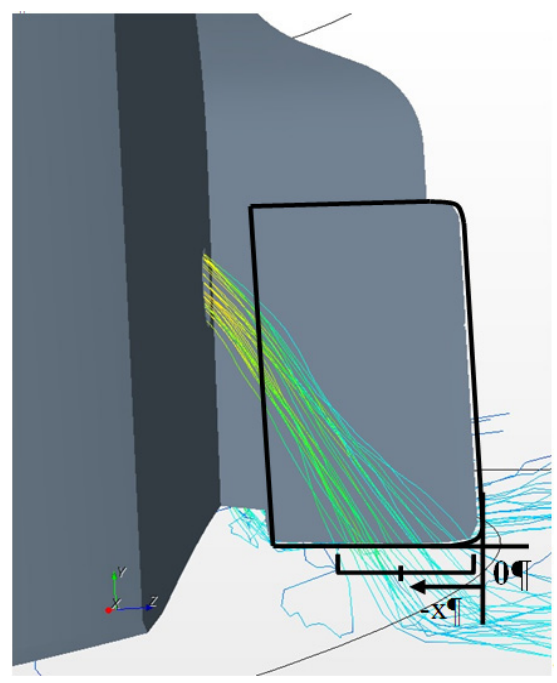

(a)

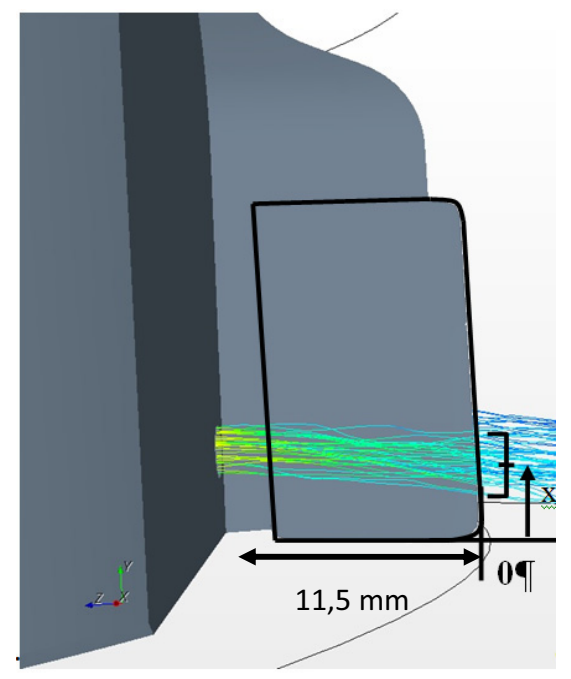

(b)

Fig. 3. Illustration of the spread measurement method on the insert surface. The spread center measured (a) at $-x$ (horizontally) and (b) at $x$ (vertically) of the cutting edge from the zero-based.

- rotation speeds of the tool which create strong aerodynamic effects due to the external tool shape;

- inclination of the canalizations to have a better oil mist spray orientation on the cutting edge.

\subsection{Influence of the canalization diameters}

The diameter of the canalizations was a significant parameter to ensure the spray efficiency. The choice of the bifurcation diameters was in relation to the diameter of the main channel. The majority of these studies was conducted within the medical community. The analysis of the air flow into the lungs for the diffusion of drugs was largely modeled [23]. The "lungs canalization" resulted in a succession of branches (ramifications). Those studies have shown that the fluid velocity was kept for defined diameters of lung canalizations [24]. The pressure lost coefficient which depended on the flow speeds and on canalization sections reduced the pressure lost [25]. It is therefore important to have a constant flow rate between the main canalization inlet and of each ramification outlet. 


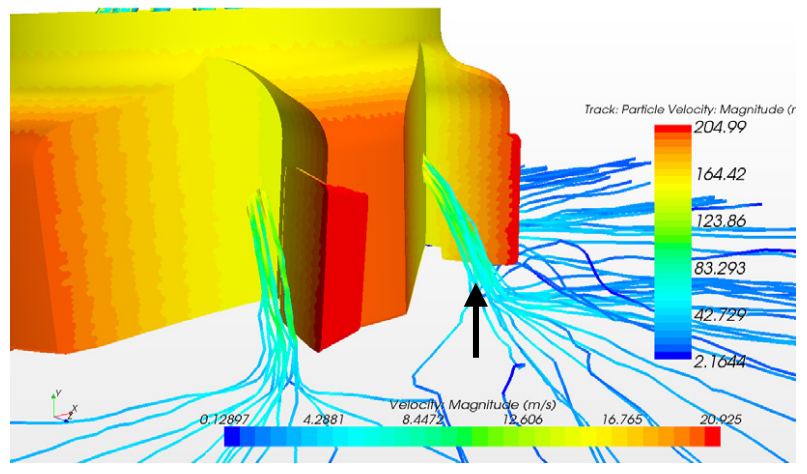

(a)

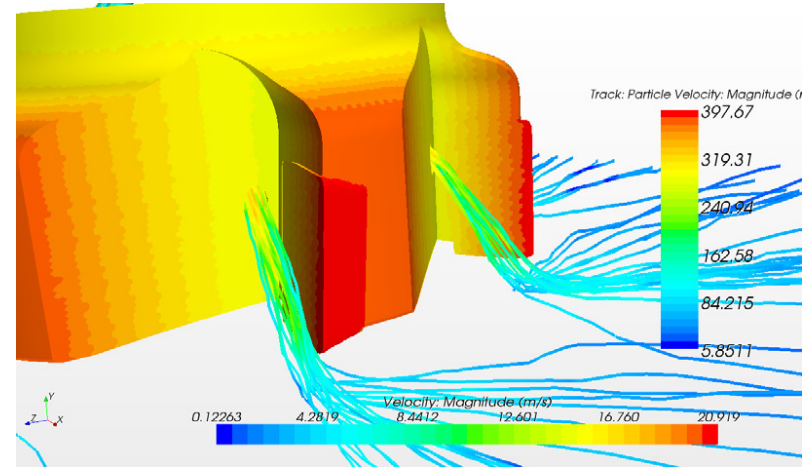

(b)

Fig. 4. Illustrations of the particle tracks outside the canalizations for (a) 0.3 bar and (b) 1 bar inlet pressures for 5000 rpm.

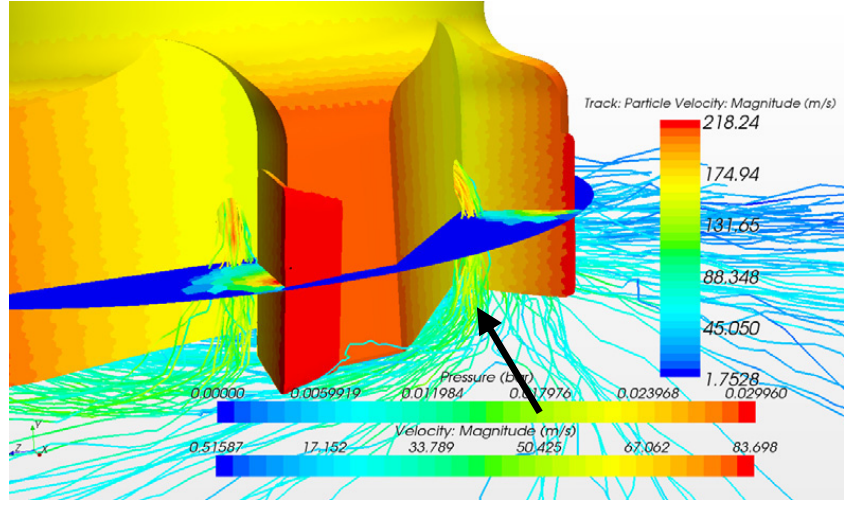

(a)

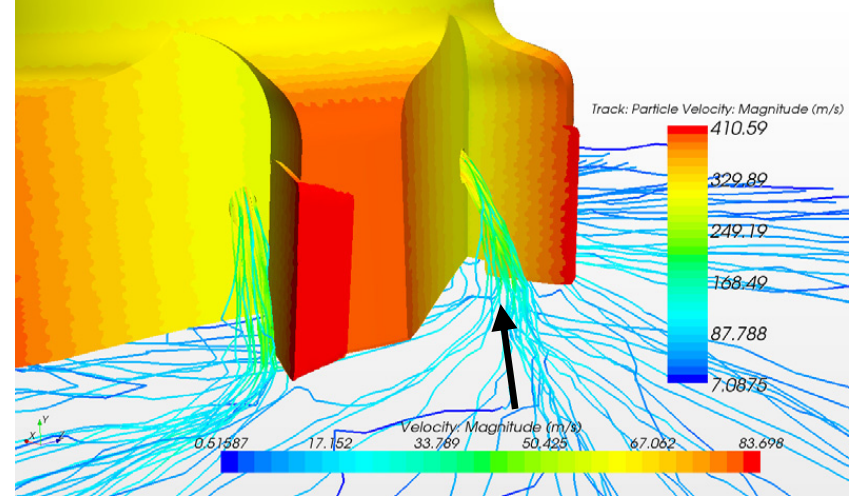

(b)

Fig. 5. Illustrations of the particle tracks outside the canalizations for (a) 0.3 bar and (b) 1 bar inlet pressures for 20000 rpm.

The conservation of the sections has to be respected to get this constant flow rate (Eq. (8)):

$$
S_{P}=\sum_{r=1}^{n} S_{r}
$$

With:

$S_{P}$ : the main section of the main canalization,

$S_{r}$ : the section of each ramification.

\subsection{Inlet pressure effect as function of the rotation speed}

Two inlet pressures (0.3 and 1 bar) as function of two rotation speeds (5000 and $20000 \mathrm{rpm}$ ) were considered in this section. The 0.77 inlet pressure and the $10000 \mathrm{rpm}$ rotation speed were not considered for illustration. This parameter set was equivalent to an average phenomenon which was not relevant to explore in this section. But some values will be presented to observe the tendency. Figures $4 \mathrm{a}$ and $4 \mathrm{~b}$ illustrated the flow of the particles at $5000 \mathrm{rpm}$ rotation speed for 0.3 and 1 bar, respectively.

For a 0.3 bar inlet pressure (Fig. 4a), the oil mist went out the canalization and sprayed on the carbide inserts halfway of the cutting tool (as shown the black arrow in Fig. 4a). The strong inlet pressure of 1 bar ensured a better oil mist spray on inserts, but did not reach the cutting tool.

Figures $5 \mathrm{a}$ and $5 \mathrm{~b}$ illustrated the flow of the particles with the same conditions as above ( 0.3 and 1 bar, respectively) for $20000 \mathrm{rpm}$ rotation speed. Because of the high rotation speed and the small inlet pressure (Fig. 5a) the oil mist had not enough velocity to be sprayed on the cutting edge. A high pressure in front of the inserts had a significant effect on the oil particles. These latter particles were stuck in the tool body and were never reached the cutting edge. For a strong inlet pressure of 1 bar, the oil particles were sprayed onto the carbide inserts, halfway of the cutting edge (as shown the black arrow on Fig. 5b).

The simulations showed for low rotation speeds, the inlet conditions did not have a significant effect on the external oil mist behavior. For high rotation speeds, a higher inlet pressure was required to ensure the spraying on the carbide inserts. Whatever the conditions, the oil mist did not reach the cutting edge. It was therefore essential to see the influence of another parameter which was the inner canalization geometries (orientation). The following Table 3 shows the outlet average velocities for different inlet pressures and rotation speeds.

Rotation speed has an effect on the average velocity. Due to the centrifugal forces, the droplet velocities 
Table 3. Outlet average velocities evolution $\left(\mathrm{m} \cdot \mathrm{s}^{-\mathbf{1}}\right)$ outside the internal channels.

\begin{tabular}{|c|c|c|c|}
\hline $\begin{array}{l}\text { Rotation speed } \\
P_{\text {Inlet }}(\text { bar })\end{array}$ & 5000 & 10000 & 20000 \\
\hline 0.3 & 155 & 170 & 175 \\
\hline 0.77 & 230 & 245 & 270 \\
\hline 1 & 300 & 310 & 315 \\
\hline
\end{tabular}

increase as the increased rotation speed. Droplet inertia is not neglected despite the small particle size considered.

\subsection{Orientation effect of the canalizations}

This part was devoted to the influence of the inner orientation of the canalization of the tool. Different orientations of the ramifications $\left(45^{\circ}, 60^{\circ}\right.$ and $75^{\circ}$ relative to the vertical axis) were taken into consideration in order to study their influence on the oil mist behavior. Numerical simulations were carried out for different rotation speeds $(5000,10000$ and $20000 \mathrm{rpm}$ ) and different inlet pressures (0.3 bar, 0.77 bar and 1 bar), from experimental data [23]. The goal of the simulations was to find favourable conditions where the oil mist reached the cutting edge. The reference was the zero-based defined in Figure 3. More spraying reached the zero-based, the better the configuration.

Figures $6 a-6 c$ illustrated the spread of the oil mist and its center positions relative to the zero-based for $45^{\circ}$, $60^{\circ}$ and $75^{\circ}$, respectively. Inlet pressures relative to the rotation speeds were considered for each illustration. Error bars showed the average spread of the oil mist on the seven inserts. The dots represent the center of the average spread of the particles on inserts.

For $45^{\circ}$ orientated canalization (Fig. 6a), the spread was regular and uniform at low rotation speed (5000 rpm), regardless the inlet pressure. Increasing the input pressure tended to reach the center of the oil mist spread to the zero-based, but still far away (about $4 \mathrm{~mm}$ ). The spread was less homogeneous for $10000 \mathrm{rpm}$. The rotation speed increase took the spread center of the oil mist away from the zero-based. For $20000 \mathrm{rpm}$ the oil particles were stuck between the tool body and inserts for 0.3 bar and 0.77 bar, because of the tool shape and the high rotation speed. With a higher pressure (1 bar) the particles moved away from the tool body and were sprayed at approximately $7 \mathrm{~mm}$ from the cutting edge (Fig. 6a).

Increasing the inclination of the canalizations at $60^{\circ}$ (Fig. 6b) put the oil mist particles impingement closer to the cutting edge of about $1 \mathrm{~mm}$ at $5000 \mathrm{rpm}$. Greater spreading of the particles was observed to $10000 \mathrm{rpm}$ at 0.77 bar inlet pressure. The spray of the particles at $20000 \mathrm{rpm}$ became homogeneous. The higher the inlet pressure the more the spray put closer to the cutting edge. The impingement of the spray was about $3 \mathrm{~mm}$ nearest to the cutting edge, relative to $45^{\circ}$.

For $75^{\circ}$ canalizations, the oil mist spray was considerably close to the cutting edge. For 5000 and $10000 \mathrm{rpm}$

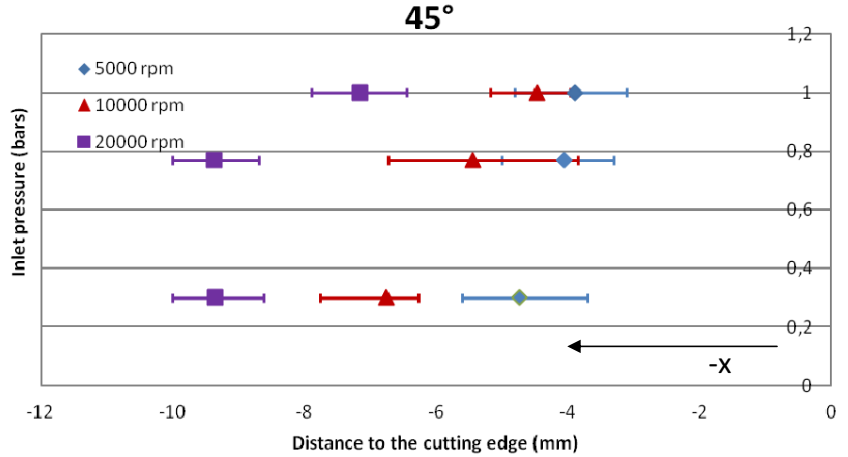

(a)

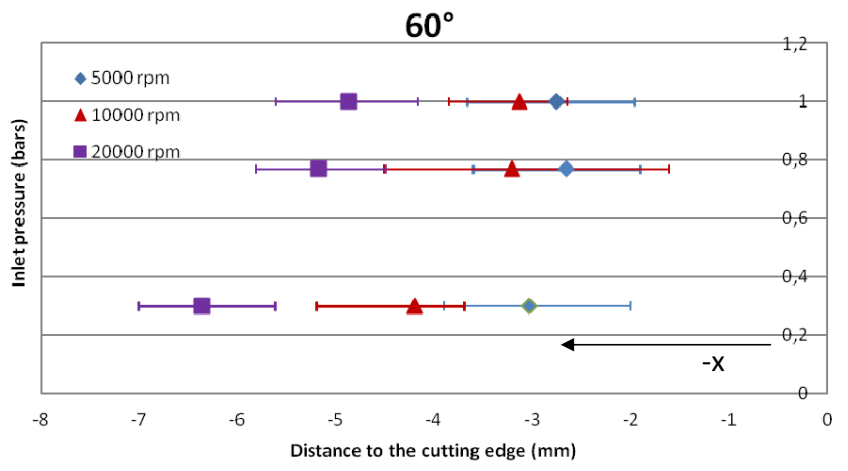

(b)

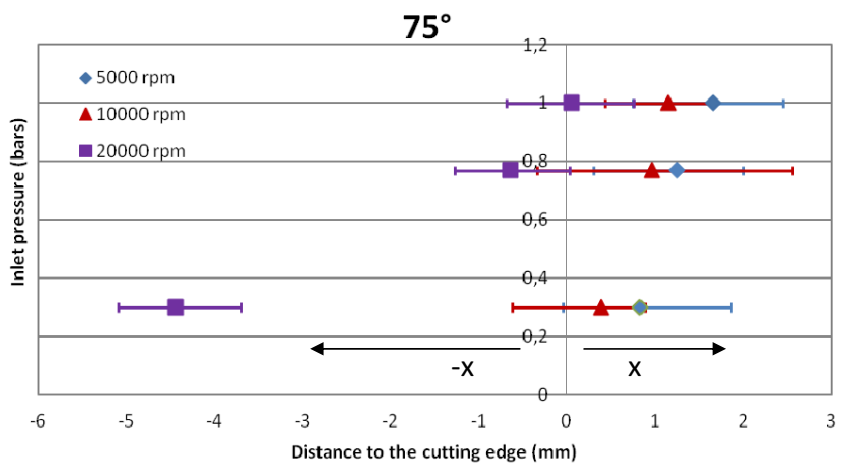

(c)

Fig. 6. Impingement of the spray center relative to the cutting edge (zero-based) at different inlet pressure $(0.3,0.77$ and 1 bar) and different speeds (5000, 10000 and $20000 \mathrm{rpm}$ ) for (a) $45^{\circ}$, (b) $60^{\circ}$ and (c) $75^{\circ}$ oriented canalizations.

rotation speeds, the mist spread on, or very close to the cutting edge (zero-based) regardless of the pressure (Fig. 6c). For high rotation speed (20000 rpm), the geometry of the rotating tool produced an aerodynamic effect which sprayed oil mist particles before the cutting edge (about $4.5 \mathrm{~mm}$ ), for low inlet pressure (0.3 bar) The following Table 4 summarized the different distances from the center of the jet to the cutting edge. The spray depended on the inlet pressure, the rotation speed and the inclination of the canalizations. The $75^{\circ}$ oriented channels sprayed the particles close to the cutting edge. 
Table 4. Summary of the distances $(\mathrm{mm})$ of the spray relative to the cutting edge zero-based on various input pressures, rotation speeds and inclinations of the canalizations.

\begin{tabular}{ccccccccccc}
\hline Rotation speeds & \multicolumn{3}{c}{5000} & \multicolumn{3}{c}{10000} & \multicolumn{3}{c}{20000} \\
\hline Pressure (bars) & 0.3 & 0.77 & 1 & 0.3 & 0.77 & 1 & 0.3 & 0.77 & 1 \\
\hline Orientations & 4.7 & 4 & 3.9 & 6.7 & 5.4 & 4.5 & 9.3 & 9.3 & 7.1 \\
$65^{\circ}$ & 3 & 2.6 & 2.7 & 4.2 & 3.2 & 3.1 & 6.3 & 5.2 & 4.9 \\
$75^{\circ}$ & 0.8 & 1.2 & 1.6 & 0.4 & 0.95 & 1.1 & 4.4 & 0.6 & 0.05 \\
\hline
\end{tabular}

This tendency was enhanced with the increase of the rotation speed.

\section{Conclusion}

This study aimed to optimize numerically the inner canalization geometries of a surfacing tool, by spraying micro quantity lubrication on carbide inserts.

First, the fluid behavior (air + oil) was provided by the transport and continuity Navier- Stokes equations. The multiphase Lagrangian model was used to simulate the particle track velocities in the flow.

Secondly, the inlet pressure, the rotation speed and the inclination of the canalizations were considered to simulate the rotation of a tool. This numerical study allowed the following conclusions:

- The flow rate conservation must be respected in order to reduce pressure losses. The flow rate conservation was provided by keeping the equality between the main canalization section and the sum of the sections of the ramifications.

- The inlet pressure must be high enough to spray the oil particles onto the carbide inserts. Due to the rotation, an aerodynamic phenomenon was noticed. With a workpiece nearby (machining condition) a high pressure was generated in front of the inserts. The fluid was deflected and therefore never reached the cutting edge.

- A $75^{\circ}$ orientation canalization was recommended to bring the oil mist on the cutting edge regardless of the rotation speed and the inlet pressure.

- The use of low inlet pressures was not recommended for high rotation speeds.

\section{References}

[1] T. Aoyama, Development of a Mixture Supply System for Machining with Minimal Quantity Lubrication, CIRP Ann. Manuf. Technol. 51 (2002) 289-292

[2] N.R. Dhar, M.W. Islam, M.A.H. Mithu, The influence of minimum quantity of lubrication (MQL) on cutting temperature, chip and dimensional accuracy in turning AISI 1040 steel, J. Mater. Process. Technol. 171 (2006) 93-99

[3] L.N. Lopez de Lacalle, C. Angulo, A. Lamikiz, J.A. Sanchez, Experimental and numerical investigation on the effect of spray cutting fluids in high speed milling, J. Mater. Process. Technol. 172 (2006) 11-15
[4] C.R.Vikram Kumar, P. Kesavan Nair, B. Ramamoorthy, Performance of TiCN and TiAlN tools in machining hardened steel under dry, wet and minimum fluid application, Int. J. Machining Machinability Mater. 3 (2008) 133-143

[5] A. Attanasio, M. Gelfi, C. Giardini, C. Remino, Minimal quantity lubrication in turning: effect on tool wear, Wear 260 (2006) 333-338

[6] Y. Kamata, T. Obikawa, High speed MQL finish turning of inconel 718 with different coated tools, J. Mater. Process. Technol. 192 (2007) 281-286

[7] T. Obikawa, Y. Kamata, Y. Asano, K. Nakayama, A.W. Otieno, Micro-liter lubrication machining of inconel 718 , Int. J. Machine Tools Manuf. 48 (2008) 1599-1604

[8] T. Obikawa, Y. Kamata, J. Shinozuka, High speed grooving applying MQL, Int. J. Machine Tools Manuf. 46 (2006) 1854-1861

[9] M. Emami, M.H. Sadeghi, A.A.D. Sarhan, Investigating the effects of liquid atomization and delivery parameters of minimum quantity lubrication on the grinding process of Al2O3 engineering ceramics, J. Manuf. Process. 15 (2013) 374-388

[10] A. Gandarias, L.N. Lopez de Lacalle, X. Aizpitarte, A. Lamikiz, Study of the performance of the turning and drilling of the austenitic stainless steels using two coolant techniques, Int. J. Machining Machinability Mater. 3 (2008) $1-17$

[11] R.P. Zeilmann, W.L. Weingaertner, Analysis of temperature during drilling of Ti6A14V with minimal quantity of lubricant, J. Mater. Process. Technol. 179 (2006) $124-127$

[12] M. Rahman, A.S. Kumar, M.U. Salam, Experimental evaluation on the effect of minimal quantities of lubricant in milling, Int. J. Machine Tool Manuf. 42 (2002) $539-547$

[13] X.X. Li, C.H. Liu, D.Y.C. Leung, K.M. Lam, Recent progress in CFD modeling of wind field and pollutant transport in street canyons, Atmospheric Environment 40 (2006) 5640-5658

[14] A. Kitagawa, Y. Murai, F. Yamamoto, Two-way coupling of Eulerian-Lagrangian model for dispersed multiphase flows using filtering functions, Int. J. Multiphase Flow 27 (2001) 2129-2153

[15] V.V. Buwa, D.S. Deo, V.V. Ranade, Eulerian-Lagrangian simulations of unsteady gas-liquid flows in bubble columns, Int. J. Multiphase Flow 32 (2006) 864-885

[16] G.F. Naterer, M. Milanez, G. Venn, On the Lagrangian/Eulerian modeling of dispersed droplet inertia: Internal circulation transition, J. Colloid Interface Sci. 291 (2005) 577-584

[17] E. Peiner, M. Balke, L. Doering, Form measurement inside fuel injector nozzle spray holes, Microelectron. Eng. 86 (2009) 984-986 
[18] D.G.E. Grigoriadis, S.C. Kassinos, Lagrangian particle dispersion in turbulent flow over a wall mounted obstacle, Int. J. Heat Fluid Flow 30 (2009) 462-470

[19] Sh. Subramaniam, Lagrangian-Eulerian methods for multiphase flows, Prog. Energy Comb. Sci. 39 (2013) $215-245$

[20] M.J. Andrews, P.J. O'Rourke, The multiphase particlein-cell (MP-PIC) method for dense particulate flows, Int. J. Multiphase Flow 22 (1996) 379-402

[21] A. Duchosal, R. Serra, R. Leroy, Static numerical simulation of oil mist particle size effects on a range of internal channel geometries of a cutting tool used in MQL strategy, Int. J. Eng. Sci. Innov. Technol. 3 (2014) 43-59
[22] A. Duchosal, R. Leroy, L. Vecellio, C. Louste, N. Ranganathan, An experimental investigation on oil mist characterization used in MQL milling process, Int. J. Adv. Manuf. Technol. 66 (2012) 1003-1014

[23] A.B. Taylor, Physicochemical processes and the formulation of dissymmetry models, Ph.D. Thesis, The Pennsylvania State University, 2006

[24] Y. Zhao, B.B. Lieber, Steady inspiratory flow in a model symmetric bifurcation, Trans. ASME 116 (1994) 488-496

[25] Y. Liu, R.M.C. So, C.H. Zhang, Modeling the bifurcating flow in a human lung airway, J. Biomech. 35 (2002) $465-473$ 